\title{
Entre o mínimo de interferência e o máximo de sutileza ${ }^{1}$
}

Among minimal interference and maximum subtlety

Rosângela Miranda Cherem² 
Entrevista concedida à Rosangela Miranda Cherem.

ROBERTA TASSINARI (Florianópolis, 1983) é graduada em Comunicação Social - Publicidade e Propaganda pela Unisul em 2005, mesma cidade em que nasceu e reside atualmente. Paralelo a essa formação, participou de oficinas de desenho, pintura e cerâmica no Centro Integrado de Cultura em Florianópolis. Logo após, mudou-se para Porto Alegre, onde morou por dois anos cursando especialização em expressão gráfica na PUCRS, e em design gráfico na UNISINOS. Em 2007 viajou para o Canadá onde cursou pintura no Emily Carr Institute of Art, em Vancouver. Dois anos depois teve sua primeira participação no circuito de arte contemporânea, com o trabalho Pinturas no 30 Salão ArtePará. Fez um mestrado em artes visuais na Universidade do Estado de Santa Catarina (UDESC) sob orientação de Regina Melim e defendeu dissertação em 2011 com o título de Raciocinio pictórico: campos de cor no espaço.Entre 2008 e 2013 participou do grupo de orientações com o artista Fernando Lindote, voltando seu interesse para a investigação de materiais de uso cotidiano, explorando suas potencialidades plásticas, pesquisa que continua desenvolvendo atualmente. Seu reconhecimento aconteceu já em 2010 através de uma menção honrosa no XIX Encontro de Artes Plásticas de Atibaia - Atibaia/SP e Prêmio Franklin Cascaes - categoria artista revelação do ano - Florianópolis/SC. Em 2015 obteve o prêmio aquisição no 43옥ão de arte contemporânea Luiz Sacilotto.

ISSN: $2175-2346$

${ }^{1}$ Entrevista com ROBERTA TASSINARI concedida a Rosângela Miranda Cherem (profa. do PPGAV- CEART-UDESC) em 24 de outubro de 2015 no espaço expositivo $O$ Sítio, localizado em Florianópolis.
${ }^{2}$ Professora na Universidade do Estado de Santa Catarina - UDESC

Florianópolis - Brasil

rosangelamcherem@gmail.com 


\section{Como você fez sua escolha pela vida artística?}

Paralelo ao curso de publicidade e propaganda busquei uma formação complementar em oficinas oferecidas no $\mathrm{CIC}$ ou cursos livres oferecidos na cidade - pintura, desenho, cerâmica e fotografia. Depois de formada fui morar em Porto Alegre para fazer pós-graduação. Continuei buscando complementar minha formação nos cursos oferecidos na cidade: aulas de história da arte, com a Maria Helena Bernardes, o processo criativo com Charles Watson, aulas particulares de pintura com a Gaby Benedict e disciplinas isoladas no curso de artes visuais da UFRGS. No ano seguinte fui para o Canadá estudar inglês e também fiz curso de pintura. Essas experiências me fizeram perceber que meu caminho profissional estava ligado à criação, mas não à criação publicitária - considerando briefing, cliente, etc - e sim aos meus interesses vinculados ao mundo da arte.

De volta à Florianópolis, em 2008, decidi fazer mestrado em artes visuais. Procurei o artista Fernando Lindote para me ajudar a elaborar um projeto de pesquisa. Nesse primeiro ano não fui aprovada, mas fiz algumas disciplinas como aluna especial, e continuei no grupo de orientações coordenado pelo Fernando e lá fiquei até 2013, quando o grupo terminou. Em 2010 iniciei o mestrado em artes visuais, orientada pela Regina Melim, na linha de processos artísticos contemporâneos, onde tive a oportunidade de fazer uma pesquisa teórico-prática sobre minha produção, que recém havia começado. $E$ isso foi fundamental para que eu pudesse entender quais questões eram importantes pra mim, o que me interessaria pesquisar;

\section{Quais as principais exposições que você participou?}

O ArtePará, em Belém, em 2009 foi o meu primeiro salão. Foi a primeira oportunidade de ver meu trabalho fora do ateliê e um contexto expositivo. No ano seguinte, 2010, fiz a instalação Croma, no Museu Histórico de Santa Catarina que me possibilitou pensar muitas questões para o trabalho. Em 2012 participei da exposição Plano-espaço no Museu de Arte de Joinville, com as artistas que também faziam parte do grupo de orientações do Lindote: Flávia Duzzo, Karina Zen, Sonia Beltrame, Neide Campos. Convidamos também a Luciana Knabben, que não era do grupo, mas o trabalho dela possibilitava um diálogo com a proposta expositiva. Atualmente, estou com a exposição MóduloCor, no O Sítio, cuja proposta consiste em apresentar alguns trabalhos que desenvolvi durante uma residência artística em NY em 2013, e outros trabalhos mais recentes que dialogam com a relação da modulação da cor e da luz através da matéria.

\section{Quais as principais questões ou conceitos que comparecem ao longo de seu trabalho?}

A exposição Reverbera, que ocorreu no MAB em março de 2015, apresentou três grupos de trabalhos. $O$ que há em comum entre eles é que eles iniciam a par- 
tir da experimentação de algum material encontrado, através das suas propriedades ou a partir da busca por um material específico para atender a uma determinada demanda. O que me interessa investigar é a contensão e a expansão da cor a partir das especificidades de diferentes materiais: opacidade, translucidez, peso, leveza e luminosidade. Há uma característica que está presente nos três grupos de trabalho que é resultante de um mesmo procedimento. O uso da fita adesiva, para isolar as áreas a serem pintadas, reforça a materialidade de cada elemento. As faixas de cor são feitas com tinta spray para que a superfície fique uniforme e evidencie as propriedades matéricas. A placa cimentícia apresenta uma cor fosca e opaca que opera em oposição à faixa de cor luminosa e translúcida que foi pintada sobre ela. A fixação na parede se dá por parafusos que deixa o material pesado e rígido suspenso, mas que por apresentar certa curvatura e estar afastado parede, favorece o abaloamento da peça distorcendo sua superfície. Busquei um material que tivesse uma característica mais quente e com uma tonalidade mais rebaixada para desenvolver uma estrutura com chapa de acrílico. O compensado atende a esta demanda e opera em oposição a cor luminosa do acrílico que se expande, tanto para a própria placa de madeira como para a parede em que está instalado. O papel poliéster apresenta uma translucidez que é interrompida pela fita adesiva opaca, ou que tem sua cor alterada pelas faixas pintadas. Trata-se de um material maleável que possibilita que sua superfície seja manipulada/curvada/dobrada favorecendo situações cromáticas.

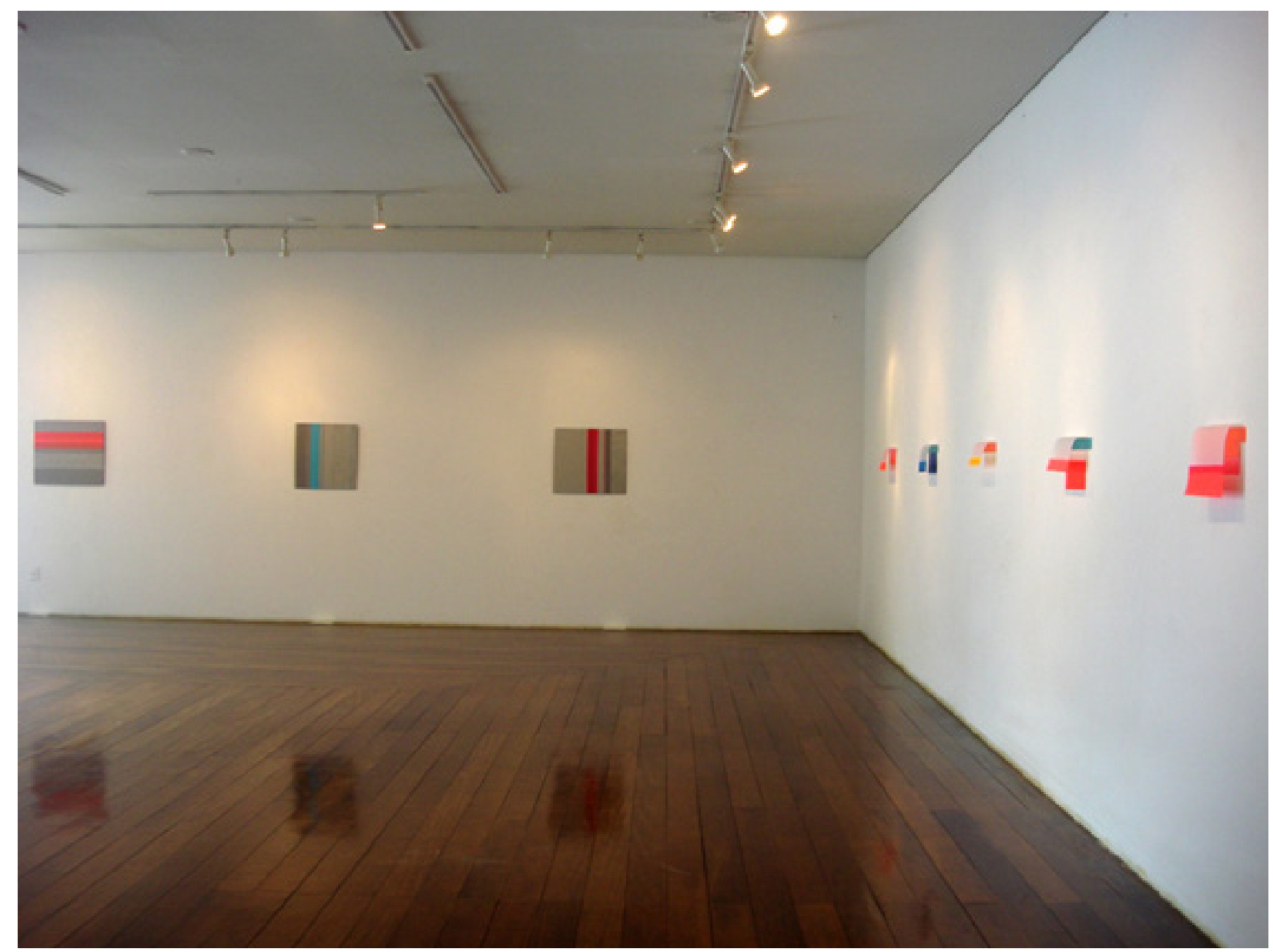

Exposição Reverbera 


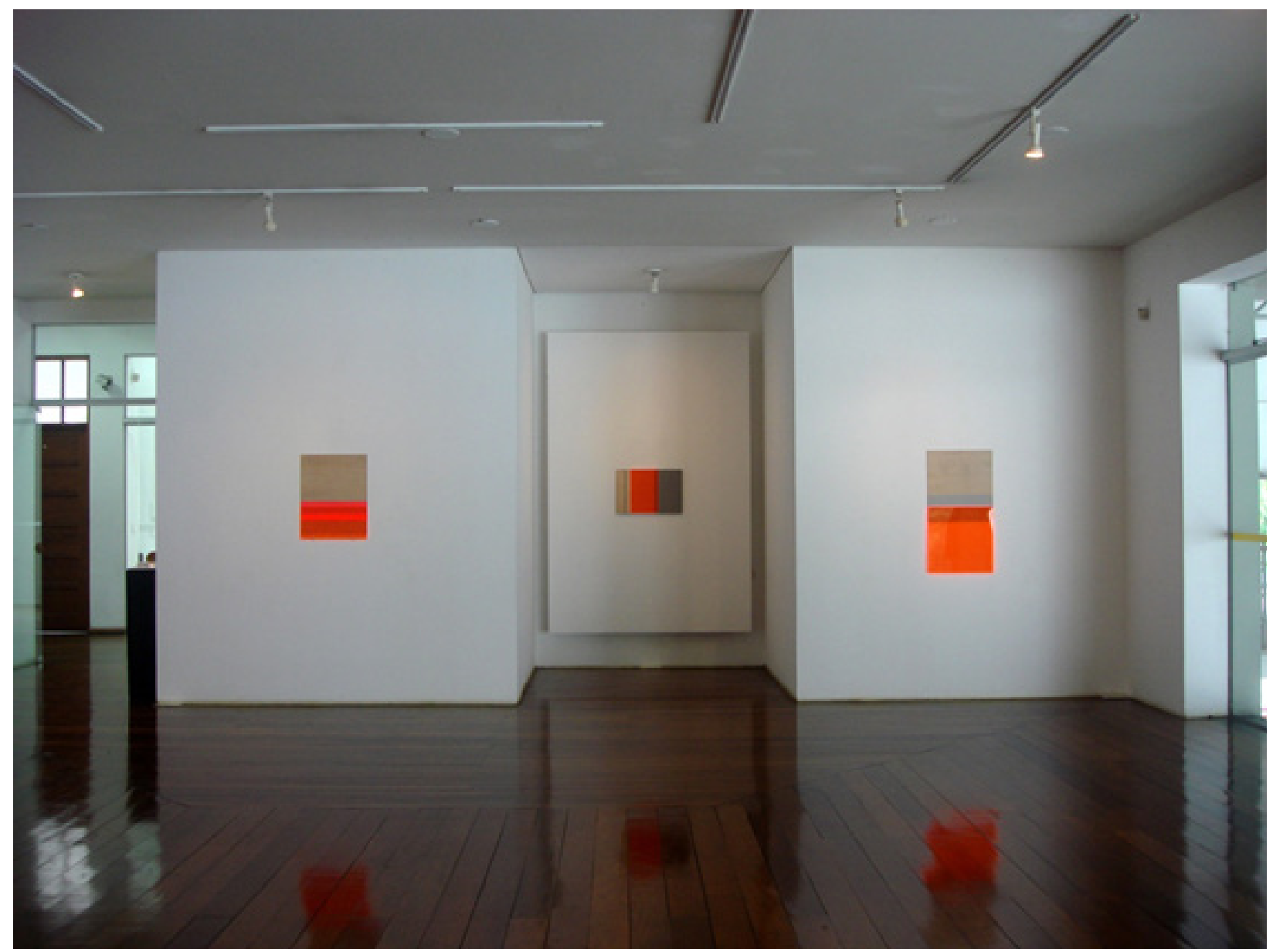

Exposição Reverbera

Atualmente estou com a exposição Módulo Cor, no O Sítio na qual selecionei trabalhos que, ainda que se apresentem em diferentes linguagens, representam um mesmo raciocínio. Para compor esta exposição priorizei os trabalhos que mantém um diálogo centrado nas questões da modulação da cor e da luz através da matéria. Para desenvolver minha pesquisa, opto pelo uso de materiais cujas propriedades me possibilitam articular elementos do campo da pintura bem como explorar suas potencialidades plásticas e expressivas, tais como: transparência/opacidade, peso/ leveza, flexibilidade/rigidez, volume/planaridade. Estes podem tanto pertencer aos modos tradicionais de pintura - tinta e tela - como ser feitos para outros fins: silicone, madeira balsa, fita adesiva, entre outros. Apresento também nesta exposição trabalhos desenvolvidos durante a residência artística que participei em Nova lorque em 2013, cuja proposta foi desenvolver trabalhos com os materiais comprados no comércio local: fitas adesivas, acrílicos em diversas cores e formatos, tecidos, alfinetes, tintas, plásticos, entre tantos outros. Essa pesquisa foi um desdobramento da minha prática no ateliê, cujo interesse se voltava para materiais que tinham uma cor vibrante e uma plasticidade que poderia ser explorada. Durante a residência pude ampliar meu repertório e agregar outras camadas de significação ao trabalho. 


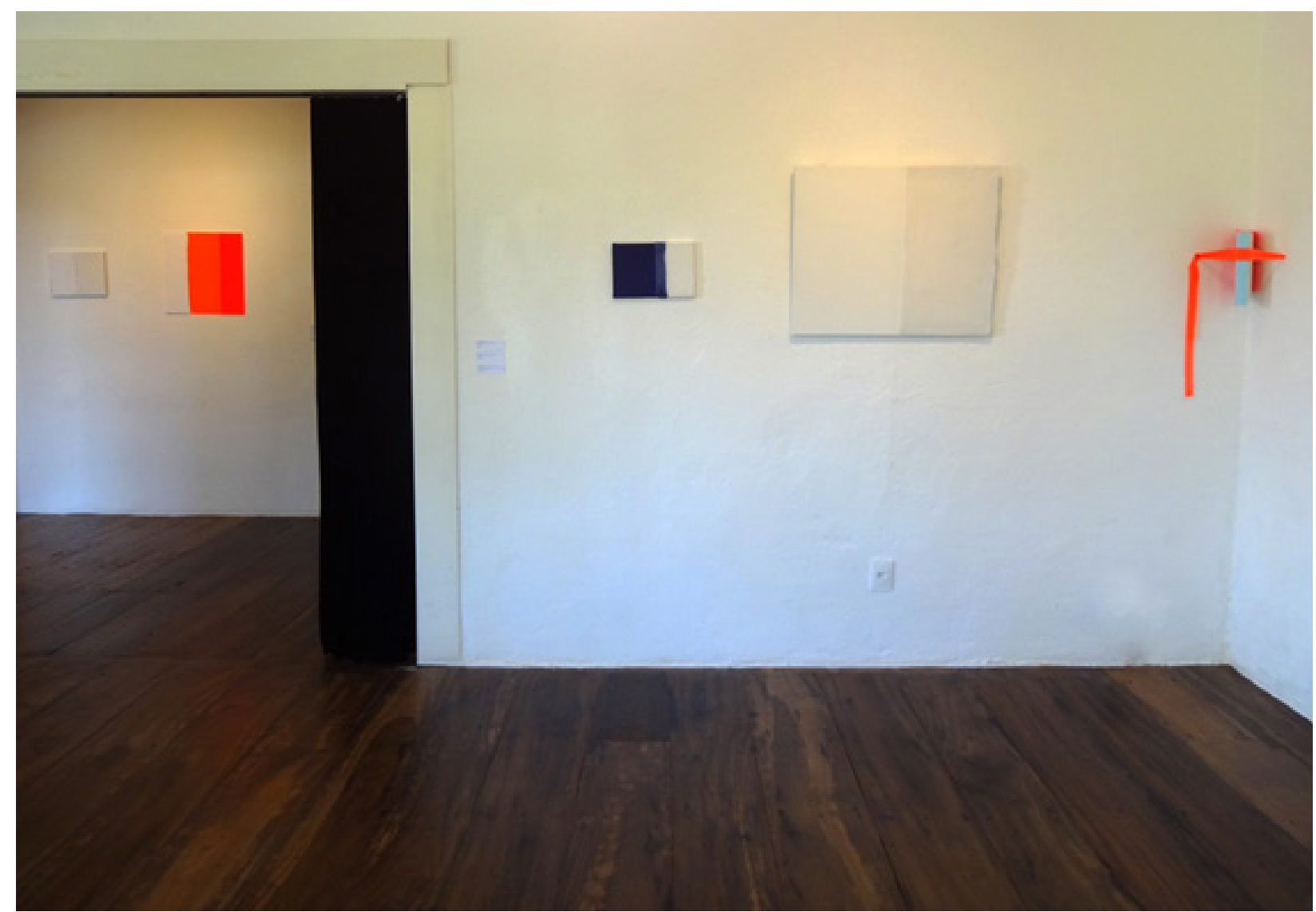

Exposição Módulo Cor

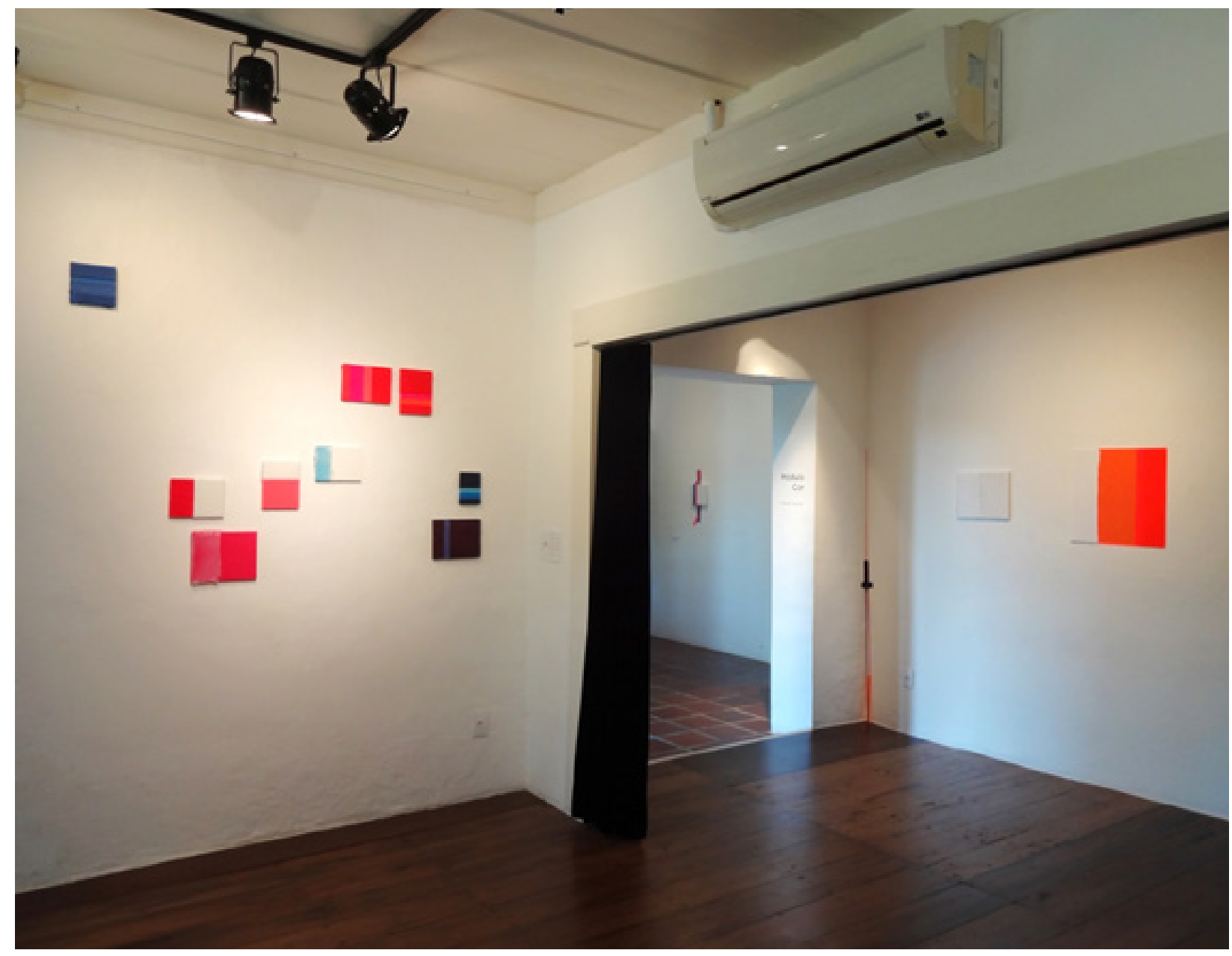


Atualmente meu interesse se volta para a experimentação de materiais que podem ser modelados e articulados favorecendo o surgimento de relações pictóricas. Em alguns trabalhos utilizo o silicone para obter uma massa que envolve a camada inferior e modula a superfície pictórica. A cor do silicone, translúcida, deixa ver a camada inferior que ora é pintada e ora preserva o branco da tela. Há o questionamento da planaridade do suporte naqueles em que construo uma camada espessa com tinta serigráfica que é isolada com fita crepe e ao ser removida deixa um degrau na superfície. Nestes trabalhos a matéria depositada na superfície possui tal espessura que ultrapassa os limites da borda tela.

Quero salientar que a relação entre os materiais tenciona e altera a dinâmica pictórica de cada trabalho. A composição desses, em sua maioria, decorre de certa negociação entre seus elementos internos: alternância das cores escuras e claras, variações de luminosidade, de massa de tinta. A cor pulsa ou se contrai, o que pode ocorrer tanto por meio da cor pintada ou da cor coletada do mundo.

\section{Como é sua rotina de trabalho?}

Flexível. Tento trabalhar das 9 às 12 e das $14: 00$ as 18-19h. Trabalhar envolve atividades e funções diversas além da prática/ do fazer artístico, como por exemplo: comprar material, organizar o ambiente de trabalho, pesquisar, olhar o que já foi feito - por mim e por outros - ver o que funciona, pensar sobre. Faz parte da rotina também montar proposta de exposição para editais e enviar portfólios para participar de salão.

\section{Falemos de seu arquivo particular: qual é sua principal fonte ima- gética e pessoal, como você escolhe os materiais e as formas que com- parecem em seu trabalho? há filmes, revistas, obras, músicas, lugares, pessoas, situações que alimentam? de que modo isso acontece?}

A fonte dos meus trabalhos vem do cotidiano, da vida, da indústria, da natureza. Ás vezes um paralelepípedo pode me interessar pelo seu volume e superfície e a partir dai iniciar uma pesquisa com outros materiais. $O$ mesmo pode ocorrer a partir de uma nova cor de spray ou de uma chapa de acrílico. Olho para os objetos do mundo ignorando a função deles. O que me interessa é a sua cor, forma, vazios, maleabilidade, e a partir daí penso de que modo posso potencializar essas características. A minha cartela de cores é bem específica. Gosto de cores que têm pouco branco em sua composição, ou seja, cores saturadas. Cores que apresentam uma vibratilidade alta. Costumo chamá-las de cores luz. E também tenho me interessado por utilizar essas cores com outras opostas, as cores sombra, que são os cinzas e marrons. Juntas, elas criam um degrau cromático onde uma favorece a outra.

Algo que tem me inquietado, já faz um tempo, é o lado oposto ao por do sol. A cada segundo as cores presentes na atmosfera mudam. Não tem como apreendê-las, nem capturá-las por muito tempo. Elas parecem que nunca se repetem, em cada lu- 
gar ocorrem de um jeito. Talvez o que eu busque no trabalho é isso: a construção de uma cor que ocorre pela soma de todas as outras que já foram usadas em trabalhos anteriores. É a construção de uma cor que ocorre através da sobreposição das outras. Eu não misturo as cores antes de ir para o trabalho. Uso as cores puras, cruas, o surgimento de novas cores ocorre no próprio trabalho. Por isso me interessam materiais transparentes e translúcidos, pois eles favorecem o surgimento de novas cores. $E$ isso é algo sutil, requer um tempo de observação em cada trabalho.

\section{Como você alimenta seu repertório quanto às referências artísticas?}

Pesquiso muito o trabalho de outros artistas. Estudo mesmo. Observo muito o trabalho, leio tudo que encontro a respeito: livros, entrevistas, textos críticos, vídeos no youtube. Aí vou entendendo o que tem no trabalho deles que me interessa e por que interessa. E por aí vai. Ao mesmo tempo, como meu trabalho consiste na investigação da matéria, estou sempre atenta a possíveis materiais que podem virar matéria prima: novas cores de tintas (acrílica, spray, guache, etc), silicones para diferentes usos - o que acarreta em pequenas diferenças de tonalidades - madeiras ou derivados, plásticos coloridos, papéis translúcidos, PVC, placas de cimento, etc. Qualquer loja pode ser que tenha algum tipo de material que eu possa vir a utilizar: Desde agropecuárias - que tem nylons coloridos vibrantes -, lojas de materiais de construção, lojas de 1,99, e também loja especializada em materiais artísticos.

\section{Que tipo de embasamento conceitual e poético você faz?}

Richard Wollheim é um teórico que me interessou bastante, principalmente na época do mestrado. Josef Albers tem um estudo das cores que me ajuda a pensar de que modo elas se relacionam. Por exemplo: ele afirma que existem três fatores que influenciam uma cor: o anteparo, a luz e o entorno. Isso é fundamental para pensar meu trabalho e o modo como articulo os elementos. Israel Pedrosa também tem uma pesquisa sobre os aspectos físicos da cor, e de que modo elas se classificam, o que contêm na sua composição, etc. igualmente, gosto de ler textos críticos sobre os artistas que tenho como referência. Isso ajuda a pensar quais as questões do meu trabalho. Entre eles, costumo acompanhar o trabalho de Tadeu Chiarelli, Alberto Tassinari, Angélica de Moraes, Cauê Alves, Rodrigo Naves, Paulo Sèrgio Duarte, Felipe Scovino, Raphael Fonseca... Além disso, tive a oportunidade de convidar algumas pessoas para escreverem sobre meu trabalho, o que possibilita um entendimento mais amplo do que proponho. Rosângela Cherem conhece meu ateliê e coloca questões que contribuem para o entendimento da minha pesquisa plástica, inclusive, escreveu um texto para o catálogo da exposição Plástica. Fernando Lindote escreveu sobre a exposição Cor-matéria, que realizei em 2010 e foi quem me acompanhou durante cinco anos, sendo fundamental na minha formação como artista. Marcelo Seixas, meu colega de mestrado, me presenteou num texto para a exposição Croma, realizada em 2010 no MHSC. E também o artista conhecido como Janga, recentemente escreveu um texto crítico muito pertinente sobre a exposição Reverbera, que fiz no MAB em março/2015. É muito bom encontrar os pares de pensamento. Isso só estimula a pesquisa e enriquece o trabalho. 


\section{Que tipo de estudo formal ou de fatura você realiza?}

Analiso as características físicas de cada material. Se for tela, percebo como é a trama, se é grossa ou fina e o que é mais importante pra mim naquele momento. $O$ mesmo ocorre com os outros materiais, como o papel poliéster, por exemplo, que possui certa translucidez - deixa ver o que tem por baixo, mas de uma forma alterada - e tem um caimento leve. Experimentei algumas relações com esse papel, até chegar na fita adesiva como elemento cromático, além de uma faixa de cor pintada com tinta spray que ora fica totalmente aparente e ora fica encoberta pelo papel. Essa sobreposição faz com que a superfície coberta de tinta tenha sua cor rebaixada e, de um modo mais turvo, reverbera. Assim, procuro fazer trabalhos monocromáticos para que seja possível a decomposição daquela cor, a partir de diferentes materiais e diferentes superfícies.

\section{Quais são suas principais referências artísticas?}

Me interesso muito pelo trabalho de artistas brasileiros relacionados ao neoconcretismo como Hélio Oiticica, particularmente no livro Aspiro ao Grande Labirinto; bem como Lygia Clark e Ligia Pape. Aloísio Carvão também é importante, pois de certa forma inaugura uma tradição da pintura no campo expandido. Os trabalhos de Luiz Henrique Schwanke, artista catarinense, também são importantes para a minha pesquisa. Jac Leirner tem um trabalho e um discurso muito claro sobre o que faz. Ela diz algo que resume boa parte do que me interessa sobre a importância de explorar as potencialidades plásticas do material. Paulo Pasta também me influencia. Gosto de pensar o modo como ele se utiliza da cor para falar sobre outras coisas. Os artistas do grupo Casa Sete têm influenciado o que estou pesquisando mais recentemente, o Paulo Monteiro com suas pinturas moles e o Rodrigo Andrade com o aspecto matérico da pintura. Sérgio Sister com as séries de trabalho Caixas de feira, Ripas e Pontaletes me ajuda a pensar o modo ele relaciona as cores sem tirar a potência de cada uma delas.

A canadense Jéssica Stockholder foi uma referência fundamental bem no começo. O modo como cada elemento era articulado no trabalho dela me ajudou a pensar de que forma eu poderia, por exemplo, suspender ou prender meus trabalhos de modo que o gancho, o prego, o parafuso ou a fita utilizados dialogassem e fossem coerentes com o trabalho. James Turrel, Olafour Eliasson e Carlos Cruz Diez me ensinam como pensar a cor-luz modificando os espaços.

\section{Como os seus trabalhos têm início e como eles se desdobram?}

A pesquisa inicia pelo material. Eu compro material a partir das características da sua superfície: transparência/opacidade; se tem brilho ou se é fosco; se tem elasticidade, se eu posso manipulá-lo ou se é rígido. É importante que esses materiais sejam novos, sem uso anterior. Pois dessa forma eles não possuem memória, nem minha 
nem de ninguém. Me dei conta disso quando comecei a ganhar alguns materiais e percebi que não conseguiria utilizá-los, pois havia informações de uso de quem havia me dado. Um amassado, uma parte mais gasta do que a houve, desbotado. Isso tudo é memória. E não quero isso. Quero partir do zero para tentar neutralizar qualquer dado pessoal daqueles materiais ou objetos. Então, experimento um material em relação ao outro, busco articulações entre eles, de modo que crie uma tensão entre as partes. E faço isso muitas vezes. Depois disso, analiso o que de fato parece interessante pra mim e o que posso descartar. Nesse processo vai muita coisa fora. Não consigo planejar ou pensar numa composição final. A composição é resultado das relações internas que surgiram dentro do trabalho. É uma consequência. E às vezes um erro pode ser uma nova possibilidade para o trabalho. Por isso é importante deixar o material se pronunciar. $O$ que tem que prevalecer é a vontade do material. Eu faço um mínimo de interferência para que os materiais mantenham o máximo de potência. 


\section{Autor}

Rosangela Miranda Cherem

Professora na Universidade do Estado de Santa Catarina - UDESC

Florianópolis - Brasil

rosangelamcheremagmail.com 